\title{
Intrauterine Growth Restriction Ameliorates the Effects of Gradual Hemorrhagic Hypotension on Regional Cerebral Blood Flow and Brain Oxygen Uptake in Newborn Piglets
}

\author{
REINHARD BAUER, BERND WALTER, RÜDIGER VOLLANDT, AND ULRICH ZWIENER \\ Institute of Pathophysiology [R.B., B.W., U.Z.], Institute of Medical Statistics, Computer Sciences and \\ Documentation [R.V.], Friedrich Schiller University, D-07740 Jena, Germany
}

\begin{abstract}
Data are scant regarding the development of cerebrovascular autoregulation in intrauterine growth-restricted (IUGR) newborns. We tested the hypothesis that IUGR improves the ability of neonates to withstand critical periods of gradual hemorrhagic hypotension by optimizing cerebrovascular autoregulation. Studies were conducted on 1-d-old anesthetized piglets divided into groups of normal weight $(\mathrm{NW}, n=14$, body weight $=1518 \pm 122 \mathrm{~g})$ and IUGR $(n=14$, body weight $=829 \pm 50 \mathrm{~g}$ ) animals. Physiologic parameters, including regional cerebral blood flow (CBF) and cerebral metabolic rate of oxygen $\left(\mathrm{CMRO}_{2}\right)$, were similar in NW and IUGR piglets under baseline conditions. Controlled arterial blood loss [hemorrhagic hypotension $(\mathrm{HH})$ ] induced a stepwise reduction of the mean arterial blood pressure of $49 \pm 3 \mathrm{~mm} \mathrm{Hg}$ (mild HH), 39 $\pm 3 \mathrm{~mm} \mathrm{Hg}$ (moderate $\mathrm{HH}$ ), and $30 \pm 3 \mathrm{~mm} \mathrm{Hg}$ (severe $\mathrm{HH}$ ) in seven NW and seven IUGR piglets $(p<0.05)$. In NW piglets, cortical $\mathrm{CBF}$ and $\mathrm{CMRO}_{2}$ was reduced already at moderate $\mathrm{HH}(p$ $<0.05$ ). A similar $\mathrm{CMRO}_{2}$ reduction occurred during severe $\mathrm{HH}$ in NW and IUGR piglets $(p<0.05)$. In addition, during mild and moderate $\mathrm{HH}$, primarily in IUGR piglets, an increase in regional
\end{abstract}

\section{ABSTRACT}

CBF of brainstem, cerebellum, and thalamus was shown compared with baseline values $(p<0.05)$. Furthermore, under these conditions, cerebral cortex blood flow was maintained in newborn IUGR animals. In contrast, NW piglets exhibited a significant reduction in CBF $(p<0.05)$ during moderate HH. Thus, IUGR resulted in an improved ability to withstand critical periods of gradual oxygen deficit as shown by improved cerebrovascular autoregulation during hemorrhagic hypotension. (Pediatr Res 56: 639-646, 2004)

$\quad$ Abbreviations
ABP, arterial blood pressure
CBF, cerebral blood flow
CMRO,
HH, cerebral metabolic rate of oxygen
IUGR, intrauterine growth restriction
MABP, mean arterial blood pressure
NW, normal-weight
PID-controller, proportional differential integral controller

Asymmetric IUGR (type II) is still an unresolved problem in perinatal medicine. Perinatal mortality is markedly increased (1-3), as well as the incidence of perinatal asphyxia, because placental insufficiency is the main cause of IUGR (4).

The perinatal morbidity and mortality of neonates after IUGR is mainly caused by postasphyxial encephalopathy (4). The most dangerous complication is brain injury secondary to hypoxic-ischemic disease, which is the predominant form of all brain injuries encountered in the perinatal period (5). Periods of arterial hypotension are frequently involved in the initial

Received May 23, 2003; accepted March 1, 2004.

Correspondence: Reinhard Bauer, M.D., Institute for Pathophysiology, Universitätsklinikum, Friedrich Schiller University, D-07740 Jena, Germany; e-mail: rbau@mti-n.mti.uni-jena.de

Supported by the Bundesministerium für Bildung und Forschung, Bonn, Germany, grant BMBF 01ZZ9104 (R.B.).

DOI: 10.1203/01.PDR.0000139425.94975.77 period of acute perinatal asphyxia (6). Cerebrovascular autoregulation protects against brain hypoperfusion, provided arterial pressure does not fall below the lower limit of the autoregulatory range. The efficiency of autoregulation to prevent hypoperfusion generally improves with increasing fetal age and maturity of the brain (7-9). This implies that the immature brain is susceptible to ischemia during hypotension (10). Therefore, poor autoregulation may place the immature brain at risk for injury $(11,12)$.

The slow down of fetal growth late in gestation after intrauterine malnutrition, although resulting in IUGR, can be regarded as a compensatory process, which enables the fetus to survive $(13,14)$. Growth reduction is primarily achieved by altering the endocrine milieu, possibly by reducing the endocrine and paracrine IGF-I activity (15) in response to impaired transplacental nutrient transfer (16). Reduced substrate consumption enables - at least at times - the prevention of a life- 
threatening imbalance between nutritional supply and demand. Therefore, the period of adequate compensation, characterized by reduced growth due to restricted nutrient availability, but widely compensated placental respiratory function (17), reflects a functional state in which contradictory effects of acceleration or delay in organ maturation including brain functional development may occur (18-22). Moreover, it should be considered that further disturbances in hormonal homeostasis during fetal life are apparently involved in permanent alterations of organ structure or function. Among others, an excess of glucocorticoids during fetal life may be associated postnatally with an altered programming of the hypothalamopituitary-adrenal axis (23), disturbed brain dopamine metabolism $(21,24)$, and altered cerebrovascular function (25).

Furthermore, an improved capacity of newborn IUGR piglets to withstand severely disturbed renal oxygenation has been reported (26). Until now, the effects of IUGR on the cerebral autoregulatory response and cerebral oxygen uptake during gradual reduction of the cerebral perfusion pressure have not been determined. Therefore, we estimated regional CBF and $\mathrm{CMRO}_{2}$ during gradual $\mathrm{HH}$ in newborn normal-weight and IUGR piglets. We used a morphometrically well-characterized state of IUGR in newborn piglets (27) and included animals with optimal vital conditions early after birth. We speculate that IUGR may improve the ability of the neonate to withstand critical periods of brain oxygen availability by gradual $\mathrm{HH}$.

\section{METHODS}

All surgical and experimental procedures were approved by the committee of the Thuringian State Government on Animal Research. Animals were obtained from a breeding farm. Delivery was observed and the viability of neonatal piglets assessed immediately after birth so that only animals with a viability score $\geq 7$ (28) were included in the study. Immediately before the onset of the experiments, animals were carried to the laboratory in a climate-controlled transport incubator (environmental temperature, $33-34^{\circ} \mathrm{C}$; time for transportation, $30-60 \mathrm{~min}$ ). Animals were divided into NW piglets $(n=14$; age, $11-26 \mathrm{~h}$; body weight, 1518 $\pm 122 \mathrm{~g})$ and IUGR piglets $(n=14$; age, $13-28 \mathrm{~h}$; body weight, $829 \pm 50 \mathrm{~g}$ ) according to their birth weight. The birth weight distribution of the breed of piglets used here (German Landrace) has been described previously (27).

Anesthesia and surgical preparation. The piglets were initially anesthetized with $1.5 \%$ isoflurane in $70 \%$ nitrous oxide and $30 \%$ oxygen by mask. The anesthesia was maintained throughout the surgical procedure with $0.8 \%$ isoflurane. Cutaneous incisions were made after s.c. instillation of a local anesthetic (Xylocitin 2\%, Jenapharm, Jena, Germany). A central venous catheter was introduced through the left external jugular vein and was used for the administration of drugs and for volume substitution [heparinized isotonic saline solution (1 IU heparin $/ \mathrm{mL}$ ): $5 \mathrm{~mL} / \mathrm{h}$ ]. An endotracheal tube was inserted through a tracheotomy. After immobilization with i.v. pancuronium bromide $(0.2 \mathrm{mg} / \mathrm{kg}$ body weight $/ \mathrm{h})$, the piglets were artificially ventilated (Servo Ventilator 900C, Siemens-Elema, Sweden). The artificial ventilation was adjusted to maintain normoxic and normocapnic blood gas values. Polyurethane catheters (inner diameter, $0.5 \mathrm{~mm}$ ) were advanced through both umbilical arteries into the abdominal aorta to record the arterial blood pressure and to withdraw reference samples for the colored microsphere technique. Another polyurethane catheter (inner diameter, $0.3 \mathrm{~mm}$ ) was inserted into the superior sagittal sinus through a midline burr hole $(3 \mathrm{~mm}$ in diameter and located $4 \mathrm{~mm}$ caudal to the bregma) and advanced to the confluence sinuum to obtain brain venous blood samples. The left ventricle was cannulated retrogradely via the right common carotid artery with a polyurethane catheter (inner diameter, 0.5 $\mathrm{mm})$. The arterial, left ventricular, and the central venous catheters were connected with pressure transducers $(\mathrm{P} 23 \mathrm{Db}$, Statham Instruments Inc., Hato Rey, Puerto Rico). Correct positioning of the catheter tips was checked by continuous pressure trace recordings and by autopsy at the end of the experiment. Body temperature was monitored by a rectal temperature probe, and was maintained throughout the general instrumentation at $38 \pm 0.3^{\circ} \mathrm{C}$ using a warmed pad and a feedback-controlled heating lamp. Physiologic parameters were recorded on a multichannel polygraph (MT95K2, AstroMed, W. Warwick, RI). The arterial blood pressure was monitored continuously, and arterial blood samples were withdrawn and analyzed at regular intervals to monitor blood gases and whole blood acid-base parameters.

Experimental protocol. After the surgical preparation had been completed, the anesthesia was reduced to $0.25 \%$ isoflurane in $70 \%$ nitrous oxide and $30 \%$ oxygen and the piglets were allowed to stabilize for $1 \mathrm{~h}$. After control values were obtained, randomly chosen NW piglets (group 3, $n=7$ ) and IUGR piglets (group $4, n=7$ ) were connected with the external ABP controller to adjust MABP sequentially at three different levels (starting with MABP-50: $\sim 50 \mathrm{~mm} \mathrm{Hg}$, followed by MABP-40: 40 mm Hg, and MABP-30: 30 mm $\mathrm{Hg}$ ) in each animal. Each level of gradually reduced MABP was maintained for about $30 \mathrm{~min}$. A complete series of values was recorded at the 25th min of every steady state period. Blood volume replacement was given after each blood withdrawal using stored heparinized blood obtained from a sibling donor piglet. The remaining NW piglets (group 1, $n=7$ ) and IUGR piglets (group 2, $n=7$ ) were submitted to all experimental procedures except the induced ABP changes and served as untreated control animals.

Gradual ABP reduction controlled by an external PIDcontroller. A detailed description of the procedure of mean arterial blood pressure adjustment at externally given set-points using an external blood pressure control loop has been given elsewhere $(29,30)$. In brief, ABP (controlled quantity) was controlled by a PID-controller running on a personal computer, by altering the blood volume by arterial blood infusion or withdrawal, respectively. An infusion/withdrawal pump was the controlling element. Because there are several nonlinear and nonstationary properties in the controlled physiologic system, the parameters of the external technical controller were searched by trial and error. Stable control of ABP was obtained by means of the integrating property of the controller in particular. The integration time constant of $\mathrm{K}_{\mathrm{I}}=6.94 \mathrm{~mm} \mathrm{Hg} \cdot \mathrm{min}^{-1}$ was found to be appropriate during all states investigated. 
Measurements. The regional CBF was measured by means of the reference sample color-labeled microsphere (Dye-Trak, Triton Technology, San Diego, CA) technique, which represents a valid alternative to the radionuclide-labeled microsphere method for organ blood flow measurement in newborn piglets without the disadvantages arising from radioactive labeling (31). Application of this technique in piglets and methodological considerations have been presented and discussed in detail elsewhere $(31,32)$. Briefly, in random color sequence, a known amount of colored polystyrene microspheres was injected into the left ventricle. A blood sample was withdrawn from the thoracic aorta as the reference sample. At the end of each experiment, the piglet brains were obtained. To retrieve the microspheres, each tissue sample was digested and then filtered under vacuum suction through an 8 - $\mu \mathrm{m}$-pore polyester-membrane filter. Colored microspheres were quantified by their dye content. The dye was recovered from the microspheres by adding dimethylformamide. The photometric absorption of each dye solution was measured by a diode-array UV/visible spectrophotometer (Model 7500, Beckman-Coulter, Inc., Fullerton, CA). Calculations were performed using MISS software (Triton Technology, San Diego, CA). The number of microspheres was calculated using the specific absorbance value of the different dyes. All reference and tissue samples contained $>400$ microspheres.

The heart rate, $\mathrm{ABP}$, arterial and brain venous $\mathrm{pH}, \mathrm{PCO}_{2}, \mathrm{Po}_{2}$, oxygen saturation, and $\mathrm{Hb}$ values were measured immediately before the microsphere injection. Blood $\mathrm{pH}, \mathrm{PCO}_{2}$, and $\mathrm{Po}_{2}$ were measured with a blood gas analyzer (model ABL50, Radiometer, Copenhagen, Denmark), and blood Hb and oxygen saturation were measured using a hemoximeter (model OSM2, Radiometer) and corrected to the body temperature of the animal at the time of sampling.

The absolute flows to the tissues measured by the colored microspheres were calculated by the formula: flow $_{\text {tissue }}=$ number of microspheres ${ }_{\text {tissue }} \cdot\left(\right.$ flow $_{\text {reference }} /$ number of microspheres $\left._{\text {reference }}\right)$. Flows were expressed in milliliters per minute per $100 \mathrm{~g}$ tissue by normalizing for tissue weight. Blood $\mathrm{O}_{2}$ content $\left(\mathrm{cO}_{2}\right)$ was calculated using the following equation:

$\mathrm{cO}_{2}\left[\mathrm{~mL} \cdot \mathrm{dL}^{-1}\right]=$

$$
\begin{aligned}
& \mathrm{cHb}\left[\mathrm{g} \cdot \mathrm{dL}^{-1}\right] \times \mathrm{sO}_{2}\left[\mathrm{mmol} \cdot \mathrm{mmol}^{-1}\right] \\
& \times 1.39\left[\mathrm{~mL} \cdot \mathrm{g}^{-1}\right]+\left(\mathrm{Po}_{2}[\mathrm{mmHg}]\right. \\
& \left.\times \alpha \mathrm{O}_{2}\left[\mathrm{~mL} \cdot \mathrm{dL}^{-1} \cdot \mathrm{mmHg}^{-1}\right]\right)
\end{aligned}
$$

to obtain the sum of oxygen that is physically dissolved and chemically bound to $\mathrm{Hb}\left[\mathrm{cHb}: \mathrm{Hb}\right.$ concentration; $\mathrm{sO}_{2}: \mathrm{O}_{2}$ saturation; $1.39\left(\mathrm{~mL} \cdot \mathrm{g}^{-1}\right)$ : theoretical oxygen capacity of $\mathrm{Hb}$; $\alpha \mathrm{O}_{2}$ : solubility of $\mathrm{O}_{2}$ in blood $=\mathrm{cHb} \times 0.000054(\mathrm{Hb}-$ dependent $\mathrm{O}_{2}$ solubility ) +0.0029 (solubility of $\mathrm{O}_{2}$ in plasma)]. Because the sagittal sinus drains the cerebral cortex, the cerebral white matter, and some deep gray structures (basal ganglia, thalamus, and hippocampus) (33), the blood flow measured to the forebrain included these structures. The $\mathrm{CMRO}_{2}$ was obtained by multiplying the blood flow to the forebrain by the cerebral arteriovenous $\mathrm{O}_{2}$ content difference. Cerebral oxygen extraction was calculated as the ratio between cerebral arteriovenous $\mathrm{O}_{2}$ content difference and arterial $\mathrm{O}_{2}$ content.

Statistical analysis. Data are reported as means \pm SD. Initial comparison was done for all parameters studied using two-way ANOVA with one factor, "treatment," which considered possible effects of gradual ABP reduction. The second factor, "stages," considered repeated measures along the experimental approach. Because in a majority of cases an interaction between the two factors was shown, we reduced the following statistical analysis on separate evaluations of the parameters without considering their correlations. Consequently, comparisons between groups were made with one-way ANOVA. Posthoc comparisons were made with Tukey's test for all pairwise multiple comparisons. Comparisons of measurements between baseline and different stages of gradual $\mathrm{ABP}$ decrease within the groups and $\mathrm{CBF}$ values of different brain regions were made with one-way ANOVA, with repeated measures. A Bonferroni adjustment was performed to evaluate significant differences. Differences were considered significant when $p<0.05$.

\section{RESULTS}

Table 1 summarizes some morphometric parameters of the experimental groups. Naturally occurring growth restriction in swine is asymmetrical, with an increase in the mean ratio of brain weight to liver weight from $0.90-0.97$ to $1.60-1.73$ ( $p<$ $0.01)$. The reduction in brain weight was quite small $(90 \%$ of $\mathrm{NW}$ group). In contrast, the decrease in liver weight (47-55\% of NW group) was similar to that in body weight (54-55\% of NW group). All differences in organ weight were significant $(p<0.01)$.

During baseline conditions, ABP, heart rate, acid-base balance, blood gas, and metabolic values were within the physiologic range and consistent with other data obtained from anesthetized and artificially ventilated newborn piglets $(34,35)$. Arterial glucose content was mildly but significantly lower in IUGR piglets $(p<0.05)$. Other physiologic values such as $\mathrm{CMRO}_{2}$ and regional CBF were also similar in NW and IUGR piglets (Table 2, Figs. 1 and 2).

Table 1. Organ weights of newborn piglets following normal growth [groups 1 (untreated, $n=7)$ and 3 (gradual HH-treated, $\mathrm{n}=7$ )] or IUGR [groups 2 (untreated, $\mathrm{n}=7$ ) and 4 (gradual HH-treated, $\mathrm{n}=7$ )]

\begin{tabular}{cccccc}
\hline & Body weight $(\mathrm{g})$ & Brain weight $(\mathrm{g})$ & Liver weight $(\mathrm{g})$ & Brain liver ratio & Brain body weight ratio \\
\hline Group 1 & $1467 \pm 85$ & $33.0 \pm 0.4$ & $37.3 \pm 6.0$ & $0.90 \pm 0.12$ & $0.023 \pm 0.001$ \\
Group 2 & $804 \pm 46^{*}$ & $29.5 \pm 0.2^{*}$ & $17.5 \pm 3.0^{*}$ & $1.73 \pm 0.30^{*}$ & $0.037 \pm 0.002^{*}$ \\
Group 3 & $1568 \pm 138$ & $33.5 \pm 0.7$ & $35.2 \pm 5.3$ & $0.97 \pm 0.14$ & $0.021 \pm 0.001$ \\
Group 4 & $854 \pm 42^{*}$ & $29.8 \pm 0.2^{*}$ & $19.4 \pm 4.3^{*}$ & $1.60 \pm 0.35^{*}$ & $0.035 \pm 0.001^{*}$ \\
\hline
\end{tabular}

Values are means $\pm \mathrm{SD}$.

$* p<0.01$, comparison between normal weight newborn piglets and IUGR ones. 
Table 2. Effect of hemorrhagic hypotension on arterial blood gases, acid-base balance, and metabolic parameters in normal weight (NW, group 1, untreated; group 3, gradual HH-treated) and IUGR (group 2, untreated; group 4, gradual HH-treated) piglets

\begin{tabular}{|c|c|c|c|c|}
\hline & Baseline & MABP-50 & MABP-40 & MABP-30 \\
\hline \multicolumn{5}{|c|}{ Heart rate $\left(\min ^{-1}\right)$} \\
\hline Group 1 & $170 \pm 23$ & $175 \pm 31$ & $191 \pm 36$ & $208 \pm 13$ \\
\hline Group 2 & $164 \pm 16$ & $185 \pm 36$ & $195 \pm 28$ & $211 \pm 19$ \\
\hline Group 3 & $202 \pm 33$ & $242 \pm 31^{*}$ & $273 \pm 14^{*}$ & $259 \pm 14^{*}$ \\
\hline Group 4 & $202 \pm 32$ & $263 \pm 25^{*}$ & $245 \pm 27^{*}$ & $238 \pm 12 *$ \\
\hline \multicolumn{5}{|c|}{ Arterial $\mathrm{PCO}_{2}(\mathrm{~mm} \mathrm{Hg})$} \\
\hline Group 1 & $40 \pm 2$ & $41 \pm 2$ & $40 \pm 2$ & $40 \pm 1$ \\
\hline Group 2 & $40 \pm 1$ & $40 \pm 2$ & $40 \pm 3$ & $39 \pm 3$ \\
\hline Group 3 & $41 \pm 4$ & $43 \pm 5$ & $42 \pm 8$ & $44 \pm 8$ \\
\hline Group 4 & $40 \pm 2$ & $43 \pm 8$ & $42 \pm 6$ & $38 \pm 8$ \\
\hline \multicolumn{5}{|l|}{ Arterial $\mathrm{pH}$} \\
\hline Group 1 & $7.46 \pm 0.02$ & $7.46 \pm 0.03$ & $7.45 \pm 0.02$ & $7.44 \pm 0.02$ \\
\hline Group 2 & $7.48 \pm 0.03$ & $7.47 \pm 0.03$ & $7.45 \pm 0.06$ & $7.46 \pm 0.05$ \\
\hline Group 3 & $7.45 \pm 0.05$ & $7.34 \pm 0.09 *$ & $7.20 \pm 0.17 *$ & $7.22 \pm 0.10^{*}$ \\
\hline Group 4 & $7.48 \pm 0.03$ & $7.33 \pm 0.10^{*}$ & $7.30 \pm 0.08^{*}$ & $7.25 \pm 0.05^{*}$ \\
\hline \multicolumn{5}{|c|}{ Arterial $\mathrm{Po}_{2}(\mathrm{~mm} \mathrm{Hg})$} \\
\hline Group 1 & $93 \pm 10$ & $92 \pm 11$ & $94 \pm 11$ & $90 \pm 20$ \\
\hline Group 2 & $107 \pm 21$ & $111 \pm 16$ & $114 \pm 24$ & $111 \pm 25$ \\
\hline Group 3 & $90 \pm 15$ & $93 \pm 19$ & $83 \pm 16$ & $90 \pm 13$ \\
\hline Group 4 & $114 \pm 33$ & $116 \pm 34$ & $97 \pm 21$ & $96 \pm 24$ \\
\hline \multicolumn{5}{|c|}{ Arterial $\mathrm{O}_{2}$ content $\left(\mathrm{mL} \cdot \mathrm{dL}^{-1}\right)$} \\
\hline Group 1 & $6.0 \pm 1.0$ & $5.9 \pm 1.1$ & $6.0 \pm 1.1$ & $5.8 \pm 0.9$ \\
\hline Group 2 & $6.0 \pm 1.5$ & $5.6 \pm 0.9$ & $5.4 \pm 0.7$ & $5.0 \pm 0.5$ \\
\hline Group 3 & $5.9 \pm 0.9$ & $3.9 \pm 0.5^{*}$ & $3.1 \pm 0.4 *$ & $2.5 \pm 0.4^{*}$ \\
\hline Group 4 & $5.9 \pm 1.5$ & $4.1 \pm 0.7^{*}$ & $3.1 \pm 1.3^{*}$ & $3.0 \pm 1.1^{*}$ \\
\hline \multicolumn{5}{|c|}{ Arterial hemoglobin content $\left(\mathrm{mMol} \cdot \mathrm{L}^{-1}\right)$} \\
\hline Group 1 & $6.2 \pm 0.9$ & $6.1 \pm 1.1$ & $6.2 \pm 1.1$ & $6.1 \pm 0.9$ \\
\hline Group 2 & $6.2 \pm 1.5$ & $5.8 \pm 0.8$ & $5.5 \pm 0.6$ & $5.1 \pm 0.5$ \\
\hline Group 3 & $6.2 \pm 0.9$ & $4.3 \pm 0.6^{*}$ & $3.4 \pm 0.5^{*}$ & $2.9 \pm 0.5^{*}$ \\
\hline Group 4 & $5.9 \pm 1.5$ & $4.1 \pm 1.7^{*}$ & $3.3 \pm 1.2^{*}$ & $3.2 \pm 1.4^{*}$ \\
\hline \multicolumn{5}{|c|}{ Arterial glucose content $\left(\mathrm{mMol} \cdot \mathrm{L}^{-1}\right)$} \\
\hline Group 1 & $5.7 \pm 1.2$ & $5.7 \pm 1.4$ & $5.2 \pm 1.0$ & $5.3 \pm 1.6$ \\
\hline Group 2 & $3.6 \pm 0.8 \S$ & $3.8 \pm 0.8 \S$ & $3.6 \pm 0.8$ & $3.7 \pm 0.5$ \\
\hline Group 3 & $5.9 \pm 1.4$ & $8.0 \pm 3.9$ & $7.1 \pm 4.4$ & $5.2 \pm 3.1$ \\
\hline Group 4 & $3.6 \pm 1.5 \S$ & $3.6 \pm 1.5 \S$ & $2.8 \pm 1.6 \S$ & $1.9 \pm 1.1 \S$ \\
\hline \multicolumn{5}{|c|}{ Arterial lactate content $\left(\mathrm{mMol} \cdot \mathrm{L}^{-1}\right)$} \\
\hline Group 1 & $2.0 \pm 0.4$ & $2.2 \pm 0.5$ & $2.4 \pm 0.6$ & $3.2 \pm 1.2$ \\
\hline Group 2 & $2.0 \pm 0.4$ & $2.2 \pm 0.4$ & $2.4 \pm 0.6$ & $3.2 \pm 1.2$ \\
\hline Group 3 & $2.7 \pm 0.9$ & $8.7 \pm 3.4^{*}$ & $12.5 \pm 3.4^{*}$ & $14.6 \pm 2.9^{*}$ \\
\hline Group 4 & $2.6 \pm 1.0$ & $6.8 \pm 2.3^{*}$ & $11.1 \pm 2.8^{*}$ & $14.4 \pm 3.4^{*}$ \\
\hline
\end{tabular}

Values are presented as means $\pm \mathrm{SD}$.

* Significant differences between untreated control (groups 1, $n=7$ ) and treated (group 3,n=7) NW or untreated control (group 2,n=7) and treated (group $4, n=7$ ) IUGR piglets at baseline or different levels of hemorrhagic hypotension (MABP-50: $\sim 50 \mathrm{~mm} \mathrm{Hg}$; MABP-40: 40 mm Hg; MABP-30: 30 mm Hg; $p<0.05$.

$\S$ Significant differences between NW and IUGR groups of same treatment; $p<0.05$.

Controlled arterial blood loss induced a stepwise MABP reduction to $75 \pm 10 \%$ (MABP-50), $58 \pm 8 \%$ (MABP-40), and $45 \pm 8 \%$ (MABP-30) of baseline in NW and IUGR piglets (Fig. $1, p<0.05$ ). This gradual HH induced a marked tachycardia, gradual reduction in arterial $\mathrm{Hb}$ content, and a resulting decrease in arterial $\mathrm{O}_{2}$ content. Furthermore, an increasing metabolic acidosis appeared, which was shown by reduced arterial $\mathrm{pH}$ and increased arterial lactate content, whereas arterial $\mathrm{PCO}_{2}$ remained unaltered (Table 2, $p<0.05$ ).

In NW piglets, $\mathrm{CMRO}_{2}$ was reduced already at moderate $\mathrm{HH}$ (Fig. $1, p<0.05$ ). A similar $\mathrm{CMRO}_{2}$ reduction occurred during severe MABP reduction in NW and IUGR piglets (Fig. $1, p<0.05)$. Cerebral $\mathrm{O}_{2}$ extraction was increased throughout the whole period of $\mathrm{HH}$ in both treated groups (Fig. 1, $p<$ $0.05)$.
During mild and moderate HH, primarily in IUGR piglets, an increase in regional $\mathrm{CBF}$ of brainstem and thalamus was shown (Fig. 2, $p<0.05$ ). Furthermore, under these conditions cerebral cortex blood flow was maintained in newborn IUGR animals. In contrast, already under moderate HH (MABP-40), NW piglets exhibited a significant reduction in CBF $(p<$ 0.05 ). A gradual blood pressure reduction to $\sim 45 \%$ of baseline (MABP-30) induced similar CBF reduction in NW and IUGR piglets $(p<0.05)$.

\section{DISCUSSION}

The main new finding in this study is that IUGR induces an increased ability to prevent a decrease in regional cerebral blood flow and oxygen uptake in newborns during progressive reduction 


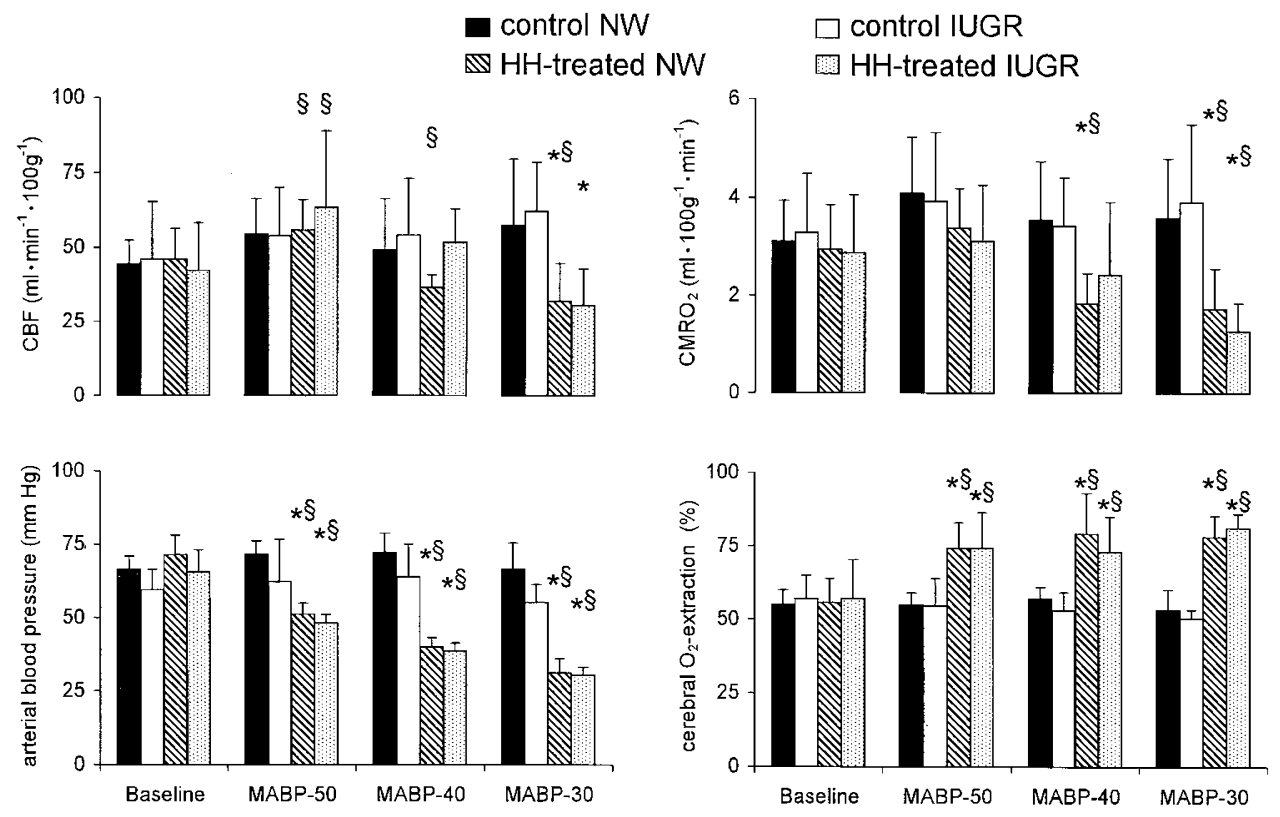

Figure 1. Effect of gradual hemorrhagic hypotension on arterial blood pressure, global $\mathrm{CBF}, \mathrm{CMRO}_{2}$, and cerebral $\mathrm{O}_{2}$ extraction in NW $(n=7$, hatched columns) and IUGR piglets ( $n=7$, dotted columns) compared with untreated NW ( $n=7$, filled columns) and untreated IUGR piglets $(n=7$, blank columns). Values are presented as means $+\mathrm{SD}$. *Comparison with untreated control animals, $p<0.05$; §comparison within every group with baseline, $p<0.05$.
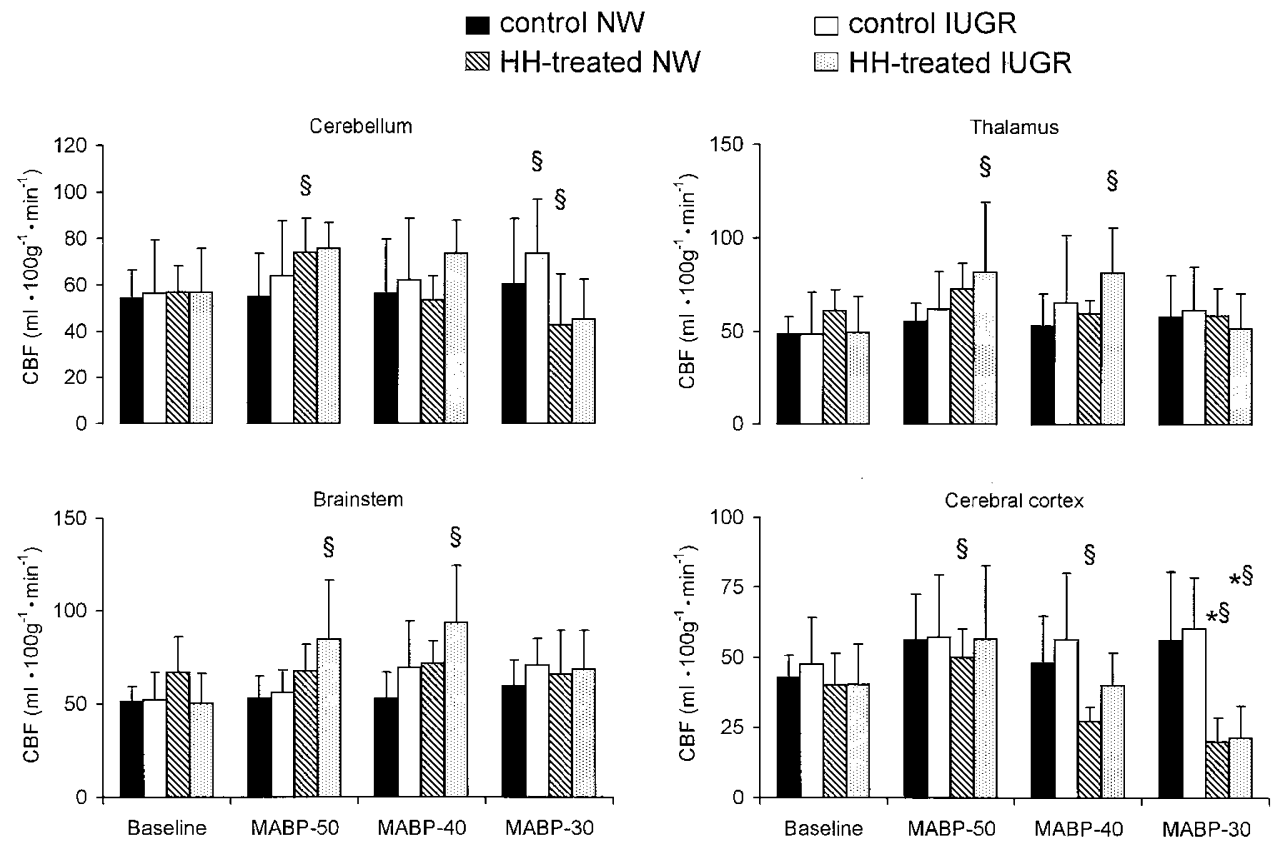

Figure 2. Effect of gradual hemorrhagic hypotension on regional CBF in NW ( $n=7$, hatched columns) and IUGR piglets ( $n=7$, dotted columns) compared with untreated NW $(n=7$, filled columns $)$ and untreated IUGR piglets $(n=7$, blank columns). Values are presented as means + SD. $*$ Comparison with untreated control animals, $p<0.05$; §comparison within every group with baseline, $p<0.05$.

of the cerebral perfusion pressure. Indeed, at moderate $\mathrm{HH}$ ( $\sim 58 \%$ of baseline) global $\mathrm{CBF}$ and $\mathrm{CMRO}_{2}$ were reduced in newborn NW piglets $(p<0.05)$, whereas IUGR animals exhibited no alterations under similar conditions. These differences, however, disappeared with increasing severity of $\mathrm{HH}$.

These findings support our assumption that, in IUGR piglets, adequate regional perfusion is maintained over a broader range due to improved cerebral autoregulation The newborn IUGR piglet is apparently able to maintain oxygen delivery to brain regions outside the cerebral cortex despite a reduction in arterial oxygen content owing to progressive blood loss and gradual HH. Therefore, under conditions of progressive cerebral perfusion pressure reduction, an adequate vascular dilation occurred in newborn IUGR piglets, whereas this was obviously insufficient in NW newborn animals.

The underlying mechanisms were not addressed by these experiments. Methodological reasons for the differences between NW and IUGR animals are unlikely because the experimental conditions were similar. However, we cannot fully exclude a different sensitivity of the cerebral vasculature to the 
pancuronium bromide used as myorelaxant. In a high dosage with ganglion blocking activity (i.e. $0.4 \mathrm{mg} / \mathrm{kg}$ ), this drug enhances CBF autoregulation, whereas in a dose more selective for the neuromuscular junction (i.e. $0.1 \mathrm{mg} / \mathrm{kg}$ ), it does not alter $\mathrm{CBF}$ autoregulation in the newborn piglet (36). We used a dosage of $0.2 \mathrm{mg} / \mathrm{kg} / \mathrm{h}$ in NW and IUGR piglets. The reported lower limit of the forebrain CBF autoregulatory range in the NW piglets is in accordance with data given in previous reports (8,36-38). Therefore, we assume that the dosage used in the recent study did not alter $\mathrm{CBF}$ autoregulation in NW animals. However, we are unable to exclude the possibility that the cerebral vasculature of IUGR animals may be more susceptible to pancuronium bromide, even if no evidence exists previously. Action time of a single dose was similar in NW and IUGR piglets.

Mild sedation by volatile anesthetics and analgesia by nitrous oxide, as used here, appears to be adequate for the experimental approach of this study. Previous studies have shown that there is no detectable influence on the cardiovascular response in newborn piglets (39). Furthermore, CBF and cerebral $\mathrm{O}_{2}$ uptake values presented in this study were similar to values obtained from newborn piglets that were treated with other drugs for general anesthesia that have been shown not to alter brain oxidative metabolism and were delivered to awake newborn piglets $(40,41)$. CBF distribution throughout the immature brain demonstrates a gradient between the brainstem (highest perfusion values) and forebrain (lowest perfusion values), thereby confirming previous findings (42). In a previous study with extensive surgical interventions, including opening the abdominal cavity, craniotomy, and ureter cannulation after retroperitoneal preparation along with $5 \mathrm{~h}$ of experimental performance, sham-operated newborn piglets showed no significant differences in ABP with only a slight increase in heart rate (by 20\%). This corresponded to a comparatively moderate increase in circulating catecholamines (epinephrine by $73 \%$, norepinephrine by $66 \%$ ) (26). This elevation in circulating catecholamines was markedly blunted compared with a rather mild hypoxic exposure. After $45 \mathrm{~min}$ of mild normocapnic hypoxia (arterial $\mathrm{O}_{2}$ saturation $=71 \pm 8 \%$, arterial $\left.\mathrm{Po}_{2}=39 \pm 7 \mathrm{~mm} \mathrm{Hg}\right)$, we found a marked increase in circulating catecholamines (epinephrine by $175 \%$, norepinephrine by $125 \%$ ) (43). Furthermore, during baseline conditions, data were within the physiologic range, consistent with other data obtained from anesthetized newborn piglets $(34,43)$, and similar to data obtained from newborn nonanesthetized piglets (35).

Mild hypoglycemia apparently did not alter CBF in IUGR piglets (Fig. 1 and 2). This is in accordance with previous findings on the effects of hypoglycemia on CBF: Mild to moderate hypoglycemia induces no more than a modest CBF increase in immature brains $(44-46)$. Furthermore, the enhanced cerebrovascular autoregulation during $\mathrm{HH}$ in the newborn IUGR animals appears not to be influenced by hypoglycemia. In adult dogs, it has been shown that moderate hypoglycemia induces no change in $\mathrm{CBF}$ at normal cerebral perfusion pressure, but does elevate the lower limit of autoregulation to a CPP of $40 \mathrm{~mm} \mathrm{Hg}$ (47). Moreover, a reduced cerebrovascular reactivity in newborn piglets (48) and a positive correlation between mean arterial blood pressure and cerebral cortical blood flow (45) suggests a loss of CBF autoregulation during hypoglycemia.

A mechanistic explanation for an enhanced cerebrovascular autoregulation in IUGR piglets during hemorrhagic hypotension cannot be derived from the present study. In addition, no other studies are known that deal with the mechanisms underlying the regulation of cerebrovascular tone in newborn IUGR individuals. Nevertheless, it is obvious that the regulatory capacity of the cerebral resistance vessels is modified, i.e. at a level of reduced perfusion pressure, where a pressure-passive alteration of blood flow appeared in NW piglets, a further relaxation of the vessel wall occurred in IUGR piglets to maintain CBF. Thus, IUGR is apparently associated with a delayed vasodilatory response at gradually reduced cerebral perfusion pressure, which could be provoked by a primarily increased vascular tone of the cerebral resistance vessels. Another possibility for a delayed vasodilatory response may result from attenuated generation of vasodilatory factors. On principal, such response patterns could be due to the chronic effects of enhanced glucocorticoid availability during fetal development of IUGR. Evidence is available that glucocorticoid activity is increased in IUGR fetuses because maternal glucocorticoids are cleared insufficiently by the placenta (see below). In a recent report it was shown that a 24 -h pretreatment with glucocorticoid induces an increase in the cerebrovascular tone of newborn piglets (49). The underlying mechanisms appear complex and presumably involve a diminished release of endothelium-derived prostanoids (50) due to inhibition of cyclooxygenase- 2 itself and/or induction of phospholipase A2 inhibitory proteins $(51,52)$. Furthermore, it has been shown that glucocorticoids down-regulate the expression of calciumdependent potassium channels in vascular smooth muscle (53) and may thereby interfere with the carbon monoxide-induced vasorelaxant response shown in newborn piglets (54).

There is evidence that an increased exposure to glucocorticoids occurs in IUGR fetuses due to disturbed placental clearance of maternal glucocorticoids. Because the concentration of circulating corticosteroid is several-fold higher in the sow than in the fetus (55), fetal protection against maternal corticosteroid intoxication is normally affected through conversion of physiologic glucocorticoids to inactive products by placental $11 \beta$-hydroxysteroid dehydrogenase $(56-58)$. This may be altered during IUGR pregnancies. Placental $11 \beta$-hydroxysteroid dehydrogenase activity was markedly reduced in the late gestational period of maternal protein-malnutrition sufficient to cause IUGR in rats (59). Recently, a significant association was found in pigs between fetal or placental size and placental $11 \beta$-HSD net dehydrogenase activity (60). In addition, IUGR rats exhibited elevated liver and brain activities of specific glucocorticoid-inducible marker enzymes (61), suggesting an increased glucocorticoid action in these organs.

The principal response of regional $\mathrm{CBF}$ regulation includes an early tendency to $\mathrm{CBF}$ increase and subsequently maintained blood flow in brainstem, cerebellum, and thalamus, but decreased $\mathrm{CBF}$ in brain cortex, under steady state conditions. Previous findings showed regional differences in the lower autoregulatory limit in newborn piglets with a most pronounced reduction in blood flow to the cerebrum, less to the cerebellum, 
and least to the brainstem $(8,62)$. These findings are in contrast to results obtained after a short-term ABP decrease ( $\sim 2 \mathrm{~min})$, where no regional differences were reported in the lower limit of autoregulation in newborn piglets (63).

In summary, this study shows that autoregulation in the brain cortex has a lower threshold in newborn IUGR piglets than in NW animals. A similar response was shown for forebrain oxygen uptake. However, the cerebral $\mathrm{O}_{2}$ extraction during gradual $\mathrm{HH}$ was not different between NW and IUGR piglets. Causal mechanisms for these differences are unknown. In contrast to the initial assumption, it seems that IUGR newborns are more capable of protecting some brain regions against hypoperfusion during hypotensive periods than NW neonates.

Acknowledgments. The authors thank Mrs. U. Jäger, Mrs. R.-M. Zimmer, and Mr. L. Wunder for skillful technical assistance.

\section{REFERENCES}

1. Ashworth A 1998 Effects of intrauterine growth retardation on mortality and morbidity in infants and young children. Eur J Clin Nutr 52:S34-S41

2. Meyberg R, Boos R, Babajan A, Ertan AK, Schmidt W 2000 Intrauterine growth restriction: perinatal mortality and postnatal morbidity in a perinatal center. Z Geburtshilfe Neonatol 204:218-223

3. Künzel W, Misselwitz B 2001 Epidemiologie der fetalen Wachstumsretardierung. Gynäkologe 34:784-792

4. Levene ML, Kornberg J, Williams TH 1985 The incidence and severity of postasphyxial encephalopathy in full-term infants. Early Hum Dev 11:21-26

5. Volpe JJ 2001 Perinatal brain injury: from pathogenesis to neuroprotection. Ment Retard Dev Disabil Res Rev 7:56-64

6. Carter BS, McNabb F, Merenstein GB 1998 Prospective validation of a scoring system for predicting neonatal morbidity after acute perinatal asphyxia. J Pediat 132:619-623

7. Hernandez MJ, Brennan RW, Bowman GS 1980 Autoregulation of cerebral blood flow in the newborn dog. Brain Res 184:199-202

8. Laptook A, Stonestreet BS, Oh W 1982 Autoregulation of brain blood flow in the newborn piglet: regional differences in flow reduction during hypotension. Early Hum Dev 6:99-107

9. Helou S, Koehler RC, Gleason CA, Jones Jr MD, Traystman RJ 1994 Cerebrovascular autoregulation during fetal development in sheep. Am J Physiol 266:H1069$\mathrm{H} 1074$

10. Tuor UI, Grewal D 1994 Autoregulation of cerebral blood flow: influence of local brain development and postnatal age. Am J Physiol 267:H2220-H2228

11. Lou HC 1994 Hypoxic-hemodynamic pathogenesis of brain lesions in the newborn. Brain Dev 16:423-431

12. Edwards AD, Azzopardi DV 2000 Perinatal hypoxia-ischemia and brain injury. Pediatr Res 47:431-432

13. Warshaw JB 1985 Intrauterine growth retardation: adaptation or pathology? Pediatrics 76:998-999

14. Aplin J 2000 Maternal influences on placental development. Semin Cell Dev Biol 11:115-125

15. Gluckman PD, Harding JE 1997 The physiology and pathophysiology of intrauterine growth retardation. Horm Res 48(suppl 1):11-16

16. Liechty EA, Boyle DW, Moorehead H, Lee WH, Yang XL, Denne SC 1999 Glucose and amino acid kinetic response to graded infusion of rhIGF-I in the late gestation ovine fetus. Am J Physiol 277:E537-E543

17. Pardi G, Cetin I, Marconi AM, Lanfranchi A, Bozzetti P, Ferrazzi E, Buscaglia M, Battaglia FC 1993 Diagnostic value of blood sampling in fetuses with growth retardation. N Engl J Med 328:692-696

18. Cook CJ, Gluckman PD, Williams C, Bennet L 1988 Precocial neural function in the growth-retarded fetal lamb. Pediatr Res 24:600-604

19. Amiel-Tison C, Pettigrew AG 1991 Adaptive changes in the developing brain during intrauterine stress. Brain Dev 13:67-76

20. Henderson-Smart DJ 1995 Postnatal consequences of chronic intrauterine compromise. Reprod Fertil Dev 7:559-565

21. Bauer R, Walter B, Vorwieger G, Bergmann R, Fuchtner F, Brust P 2001 Intrauterine growth restriction induces up-regulation of cerebral aromatic amino acid decarboxylase activity in newborn piglets: [18F]fluorodopa positron emission tomographis study. Pediatr Res 49:474-480

22. Bauer R, Walter B, Bauer K, Klupsch R, Patt S, Zwiener U 2002 Intrauterine growth restriction reduces nephron number and renal excretory function in newborn piglets. Acta Physiol Scand 176:83-90

23. Matthews SG 2002 Early programming of the hypothalamo-pituitary-adrenal axis. Trends Endocrinol Metab 13:373-380

24. Diaz R, Ogren SO, Blum M, Fuxe K 1995 Prenatal corticosterone increases spontaneous and d-amphetamine induced locomotor activity and brain dopamine metabolism in prepubertal male and female rats. Neuroscience 66:467-473
25. Lamireau D, Nuyt AM, Hou X, Bernier S, Beauchamp M, Gobeil F, Jr., Lahaie I, Varma DR, Chemtob S 2002 Altered vascular function in fetal programming of hypertension. Stroke 33:2992-2998

26. Bauer R, Walter B, Zwiener U 2000 Effect of severe normocapnic hypoxia on renal function in growth-restricted newborn piglets. Am J Physiol Regul Integr Comp Physiol 279:R1010-R1016

27. Bauer R, Walter B, Hoppe A, Gaser E, Lampe V, Kauf E, Zwiener U 1998 Body weight distribution and organ size in newborn swine (Sus scrofa domestica) - a study describing an animal model for asymmetrical intrauterine growth retardation. Exp Toxicol Pathol 50:59-65

28. De Roth L, Downie HG 1976 Evaluation of viability of neonatal swine. Can Vet J 17:275-279

29. Bauer R, Hoyer D, Walter B, Gaser E, Kluge H, Zwiener U 1997 Changed systemic and cerebral hemodynamics and oxygen supply due to gradual hemorrhagic hypotension induced by an external PID-controller in newborn swine. Exp Toxicol Pathol 49:469-476

30. Hoyer D, Bauer R, Walter B, Zwiener U 1997 Adjustment of reduced arterial blood pressure - a tool for investigations into gradually reduced brain function. Biomed Tech (Berl) 42:284-290

31. Walter B, Bauer R, Gaser E, Zwiener U 1997 Validation of the multiple colored microsphere technique for regional blood flow measurements in newborn piglets. Basic Res Cardiol 92:191-200

32. Bauer R, Walter B, Wurker E, Kluge H, Zwiener U 1996 Colored microsphere technique as a new method for quantitative-multiple estimation of regional hepatic and portal blood flow. Exp Toxicol Pathol 48:415-420

33. Coyle MG, Oh W, Stonestreet BS 1993 Effects of indomethacin on brain blood flow and cerebral metabolism in hypoxic newborn piglets. Am J Physiol 264:H141-H149

34. Lerman J, Oyston JP, Gallagher TM, Miyasaka K, Volgyesi GA, Burrows FA 1990 The minimum alveolar concentration (MAC) and hemodynamic effects of halothane, isoflurane, and sevoflurane in newborn swine. Anesthesiology 73:717-721

35. Eisenhauer CL, Matsuda LS, Uyehara CF 1994 Normal physiologic values of neonatal pigs and the effects of isoflurane and pentobarbital anesthesia. Lab Anim Sci 44:245-252

36. Chemtob S, Barna T, Beharry K, Aranda JV, Varma DR 1992 Enhanced cerebral blood flow autoregulation in the newborn piglet by d-tubocurarine and pancuronium but not by vecuronium. Anesthesiology 76:236-244

37. Leffler CW, Busija DW, Beasley DG, Fletcher AM 1986 Maintenance of cerebral circulation during hemorrhagic hypotension in newborn pigs: role of prostanoids. Circ Res 59:562-567

38. Chemtob S, Beharry K, Rex J, Varma DR, Aranda JV 1990 Prostanoids determine the range of cerebral blood flow autoregulation of newborn piglets. Stroke 21:777-784

39. Gootman PM, Buckley NM, Gootman N, Crane LA, Buckley BJ 1978 Integrated cardiovascular responses to combined somatic afferent stimulation in newborn piglets. Biol Neonate 34:187-198

40. Flecknell PA, Wootton R, John M 1983 Cerebral blood flow and cerebral metabolism in normal and intrauterine growth retarded neonatal piglets. Clin Sci (Lond) 64:161165

41. Anday EK, Lien R, Goplerud JM, Kurth CD, Shaw LM 1993 Pharmacokinetics and effect of cocaine on cerebral blood flow in the newborn. Dev Pharmacol Ther 20:35-44

42. Ashwal S, Dale PS, Longo LD 1984 Regional cerebral blood flow: studies in the fetal lamb during hypoxia, hypercapnia, acidosis and hypotension. Pediatr Res 18:13091316

43. Bauer R, Walter B, Gaser E, Rosel T, Kluge H, Zwiener U 1998 Cardiovascular function and brain metabolites in normal weight and intrauterine growth restricted newborn piglets - effect of mild hypoxia. Exp Toxicol Pathol 50:294-300

44. Mujsce DJ, Christensen MA, Vannucci RC 1989 Regional cerebral blood flow and glucose utilization during hypoglycemia in newborn dogs. Am J Physiol 256:H1659H1666

45. Anwar M, Vannucci RC 1988 Autoradiographic determination of regional cerebral blood flow during hypoglycemia in newborn dogs. Pediatr Res 24:41-45

46. Ruth VJ, Park TS, Gonzales ER, Gidday JM 1993 Adenosine and cerebrovascular hyperemia during insulin-induced hypoglycemia in newborn piglet. Am J Physiol 265:H1762-H1768

47. Sieber FE, Koehler RC, Derrer SA, Saudek CD, Traystman RJ 1990 Hypoglycemia and cerebral autoregulation in anesthetized dogs. Am J Physiol 258:H1714-H1721

48. St Jacques PJ, Kirsch JR, Diringer MN, Traystman RJ 1993 MK-801 does not prevent impaired cerebrovascular reactivity to $\mathrm{CO}_{2}$ during hypoglycemia in piglets. Am J Physiol 264:H2124-H2130

49. Heinonen K, Fedinec A, Leffler CW 2003 Dexamethasone pretreatment attenuates cerebral vasodilative responses to hypercapnia and augments vasoconstrictive responses to hyperventilation in newborn pigs. Pediatr Res 53:260-265

50. Wagerle LC, DeGiulio PA, Mishra OP, Delivoria-Papadopoulos M 1991 Effect of dexamethasone on cerebral prostanoid formation and pial arteriolar reactivity to $\mathrm{CO}_{2}$ in newborn pigs. Am J Physiol 260:H1313-H1318

51. Hirata F, Schiffmann E, Venkatasubramanian K, Salomon D, Axelrod J 1980 A phospholipase A2 inhibitory protein in rabbit neutrophils induced by glucocorticoids. Proc Natl Acad Sci U S A 77:2533-2536

52. Parfenova H, Neff III RA, Alonso JS, Shlopov BV, Jamal CN, Sarkisova SA, Leffler CW 2001 Cerebral vascular endothelial heme oxygenase: expression, localization, and activation by glutamate. Am J Physiol Cell Physiol 281:C1954-C1963

53. Brem AS, Bina RB, Mehta S, Marshall J 1999 Glucocorticoids inhibit the expression of calcium-dependent potassium channels in vascular smooth muscle. Mol Genet Metab 67:53-57 
54. Leffler CW, Nasjletti A, Yu C, Johnson RA, Fedinec AL, Walker N 1999 Carbon monoxide and cerebral microvascular tone in newborn pigs. Am J Physiol 276:H1641-H1646

55. Klemcke HG 1995 Placental metabolism of cortisol at mid- and late gestation in swine. Biol Reprod 53:1293-1301

56. Murphy BE 1981 Ontogeny of cortisol-cortisone interconversion in human tis sues: a role for cortisone in human fetal development. J Steroid Biochem 14:811-817

57. Brown RW, Chapman KE, Edwards CR, Seckl JR 1993 Human placental 11 beta-hydroxysteroid dehydrogenase: evidence for and partial purification of a distinct NAD-dependent isoform. Endocrinology 132:2614-2621

58. Klemcke HG, Christenson RK 1996 Porcine placental 11 beta-hydroxysteroid dehydrogenase activity. Biol Reprod 55:217-223
59. Langley-Evans SC, Phillips GJ, Benediktsson R, Gardner DS, Edwards CR, Jackson AA, Seckl JR 1996 Protein intake in pregnancy, placental glucocorticoid metabolism and the programming of hypertension in the rat. Placenta 17:169-172

60. Klemcke HG 2000 Dehydrogenase and oxoreductase activities of porcine placental 11beta-hydroxysteroid dehydrogenase. Life Sci 66:1045-1052

61. Langley-Evans SC, Gardner DS, Jackson AA 1996 Maternal protein restriction influences the programming of the rat hypothalamic-pituitary-adrenal axis. J Nutr $126: 1578-1585$

62. Laptook AR, Stonestreet BS, Oh W 1983 Brain blood flow and $\mathrm{O}_{2}$ delivery during hemorrhagic hypotension in the piglet. Pediatr Res 17:77-80

63. Chemtob S, Beharry K, Rex J, Varma DR, Aranda JV 1990 Changes in cerebrovascular prostaglandins and thromboxane as a function of systemic blood pressure. Cerebral blood flow autoregulation of the newborn. Circ Res 67:674-682 